\title{
PENGEMBANGAN MODEL BISNIS AGROINDUSTRI GULA KELAPA KRISTAL BERIODIUM
}

\section{BUSINESS MODEL DEVELOPMENT OF IODIZED COCONUT PALM SUGAR AGRO-INDUSTRY}

\author{
Dian Novitasari ${ }^{\star}$ dan Hety Handayani Hidayat
}

Program Studi Teknik Pertanian, Fakultas Pertanian, Universitas Jenderal Soedirman Jl. Dr. Soeparno-Karangwangkal, Purwokerto Utara, Banyumas 53122, Jawa Tengah, Indonesia E-mail: diannov.tep@unsoed.ac.id

Makalah: Diterima 10 Desember 2020; Diperbaiki 01 Maret 2021; Disetujui 30 Maret 2021

\begin{abstract}
This research was conducted with the aim of analyzing the business model of the iodized coconut sugar agro-industry using the canvas business model approach. This study used the Business Model Canvas tool. The data collection method was done by interviewing and filling out a questionnaire. The results showed that the results of the business model development were: a) customer segments include Disorders due to Iodine Deficiency (IDD), diabetics, and coconut sugar consumers; b) the proportion of value includes BPOM distribution permit, halal certificate, benefits (iodine and low GI), patents, and attractive packaging; c) distribution channels include direct sales (outlets), consignment (supermarkets / minimarkets, gift shops and pharmacies / drugstores), and online sales (medsos); d) customer relations include exhibitions, promotions via social media, inter-city services, and customer service; e) revenue streams including product sales; f) key resources include technological resources (machines and production equipment), human resources, and intellectual resources (patents); g) key activities include procurement of raw materials, production processes, distribution and promotion; $h$ ) partnerships include crystal coconut sugar producers; and i) the cost structure includes fixed and variable costs.
\end{abstract}

Keywords: business model, crystal coconut sugar, iodized coconut palm sugar

\section{ABSTRAK}

Penelitian ini dilakukan dengan tujuan menganalisis model bisnis agroindustri gula kelapa beriodium dengan menggunakan pendekatan model bisnis kanvas. Penelitian ini menggunakan perangkat Bisnis Model Canvas. Metode pengumpulan data dilakukan dengan wawancara dan pengisian kuesioner. Hasil penelitian menunjukkan bahwa hasil pengembangan model bisnis, yaitu: a) segmen pelanggan meliputi Gangguan Akibat Kekurangan Iodium (GAKI), keturunan diabet, dan konsumen gula kelapa; b) proporsi nilai meliputi adanya ijin edar BPOM, adanya sertifikat halal, manfaat (iodium dan IG rendah), paten, dan kemasan menarik; c) saluran distribusi meliputi penjualan langsung (gerai), konsinyasi (supermarket/minimarket, toko oleh-oleh dan apotik/toko obat), dan penjualan online (medsos); d) hubungan pelanggan meliputi pameran, promosi via medsos, layanan antar dalam kota, dan layanan customer service; e) arus pendapatan meliputi penjualan produk; f) sumber daya kunci meliputi sumber daya teknologi (mesin dan peralatan produksi), sumber daya manusia, dan sumber daya intelektual (paten); g) aktivitas kunci meliputi pengadaan bahan baku, proses produksi, ditribusi, dan promosi; h) kemitraan meliputi produsen gula kelapa kristal; dan i) struktur biaya meliputi biaya tetap dan variabel.

Kata kunci: model bisnis, gula kelapa beriodium, gula kelapa kristal

\section{PENDAHULUAN}

Tanaman kelapa merupakan tanaman perkebunan unggulan di Kabupaten Banyumas, Prov. Jawa Tengah dengan luasan mencapai 14.647,3 Ha pada tahun 2018 (BPS, 2020). Nilai tersebut tentunya jauh lebih besar jika dibandingkan dengan luasan tanaman karet dan kopi yang hanya mencapai 184,7 Ha dan 313,4 Ha. Salah satu upaya yang dilakukan dalam pemanfaatan tersebut adalah dengan penyadap nira dari tanaman kelapa yang kemudian diolah menjadi gula kelapa.

Hal tersebut menjadikan Kabupaten Banyumas sebagai salah satu sentra penghasil gula kelapa di Provinsi Jawa Tengah. Menurut Satriani dan Edy (2018) terdapat 26.959 pengrajin gula kelapa di
Kabupaten Banyumas dengan jumlah produksi sebanyak $176.039 \mathrm{~kg} /$ hari atau setara dengan 63.374.270,40 kg/th. Jumlah unit usaha tersebut menggambarkan prospek bisnis gula kelapa yang cerah dan menjajikan. Di sisi lain, hal ini mengakibatkan ketatnya persaingan usaha dan munculnya berbagai inovasi gula kelapa di pasaran mulai dari gula kelapa cetak, gula kelapa krital, gula kelapa dengan fortifikasi rempah, dan masih banyak lagi.

Masing-masing unit usaha tersebut akan selalu berusaha mencari keunggulan kompetitif dan melakukan diversifikasi produk gula kelapa yang diproduksinya, sehingga pelaku usaha selalu berlomba-lomba untuk menghasilkan inovasi gula kelapa. Salah satu unit usaha yang menangkap 
peluang ini dengan melakukan inovasi terhadap gula kelapa adalah agroindustri gula kelapa kristal beriodium. Gula kelapa kristal beriodium merupakan inovasi gula kelapa krital dengan fortifikasi iodium, sehingga dengan dilakukannya fortifikasi tersebut dapat dijadikan alternatif dalam penanggulangan masalah kekurangan iodium.

Inovasi ini tentunya memberikan peluang tersendiri bagi agroindustri tersebut selaku produsen gula kelapa kristal beriodium dalam bersaing dengan usaha sejenis, karena memiliki keunggulan dalam hal kesehatan. Namun, di sisi lain gula kelapa kristal beriodium merupakan produk baru. Oleh karena itu, agroindustri tersebut perlu terus untuk mengembangkan usahanya agar dapat bertahan terhadap persaingan usaha mengingat banyaknya jumlah pesaing usaha gula kelapa khususnya di Kabupaten Banyumas, Jawa Tengah. Berdasarkan permasalahan tersebut maka diperlukan suatu perumusan model bisnis dan pemetaan strategi bisnis yang akan dijalankan. Hal tersebut dikarenakan model bisnis bersifat dinamis mengikuti perubahan lingkungan, sehingga perlu dilakukan rencana pengembangan terhadap model bisnis yang sudah ada (Tokarski et al., 2017).

Salah satu cara yang dapat dilakukan oleh agroindustri gula kristal beriodium adalah dengan mengembangkan model bisnis baru yang relevan dengan tren zaman dan pasar, sehingga dapat mencapai visi dan misi dari agroindustri tersebut. Salah satu perangkat yang dapat digunakan dalam memetakan model bisnis yang sudah ada dan mengembangkan model bisnis baru dengan sederhana dan mudah dipahami Business Model Canvas (BMC) (Nurhakim et al., 2018; Sholihah dan Iqbal, 2018; Herawati et al., 2019). Menurut Sholihah dan Iqbal (2018), pemetaan model bisnis tersebut dilakukan melalui sembilan blok bangunan yang meliputi segmen pelanggan, proposisi nilai, saluran, hubungan pelanggan, arus pendapatan, sumberdaya kunci, aktivitas kunci, kemitraan utama, dan struktur biaya.

Berdasarkan uraian tersebut, maka penulis tertarik untuk melakukan penelitian dengan tujuan menganalisis model bisnis agroindustri gula kelapa beriodium dengan menggunakan pendekatan model bisnis kanvas. Fokus penelitian ini adalah menganalisis model bisnis saat ini dan faktor kunci apa saja yang memengaruhi strategi pengembangan agroindustri gula kelapa beriodium. Penelitian ini diharapkan dapat memberikan manfaat untuk memberikan rumusan kebijakan-kebijakan untuk pengembangan usaha agroindustri gula kelapa kristal beriodium dimasa yang akan datang.

\section{METODE PENELITIAN}

\section{Metode}

Bahan yang digunakan dalam penelitian ini adalah data hasil wawancara dengan pihak manajemen agroindustri gula kelapa beriodium dan pengisian kuesioner dari responden penelitian yang terdiri dari konsumen dan potensial market (konsumen gula kelapa, keturunan diabet, dan yang mengalami Gangguan Akibat Kekurangan Iodium (GAKI) dari gula kelapa beriodium yang berjumlah 100 orang.

Penelitian ini dilaksanakan selama 5 bulan dari bulan Agustus-Desember 2020. Penelitian dilaksanakan di agroindustri gula kelapa kristal beridiodium di Kabupaten Banyumas. Pemilihan lokasi tersebut dilakukan secara sengaja yaitu dengan mempertimbangkan bahwa agroindustri gula kelapa kristal beriodium adalah sebagai unit usaha gula kelapa kristal beriodium dan Kabupaten Banyumas merupakan wilayah pemasaran dari gula kelapa kristal beriodium. Jenis data yang digunakan dalam penelitian ini adalah data primer yang didapatkan dari hasil wawancara dengan pihak manajemen agroindustri dan dari hasil pengisian kueioner responden.

Tahapan penelitian yang dilakukan meliputi (Gambar 1):

1. Pembuatan hipotesis model bisnis kanvas Tahapan awal yang dilakukan dari penelitian ini adalah membuat hipotesis terhadap model bisnis dari hasil wawancara dengan pihak manajemen agroindustri gula kelapa kristal beriodium. Tahapan ini digunakan sebagai asumsi awal dari agroindustri yang dijalankan. Hipotesis tersebut meliputi:

a. Segmen pelanggan yang merupakan gambaran orang ataupun organisasi yang ingin dijangkau oleh agroindutri.

b. Proporsi nilai yang merupakan gambaran nilai dari produk dan layanan yang ingin diberikan oleh agroindustri kepada segmen pelanggan.

c. Saluran yang merupakan gamabran cara agroindustri dalam berkomunikasi dan menjanggau segmen pelanggan.

d. Hubungan pelanggan yang menggambarkan jenis hubungan yang dibangun agroindustri dengan segmen pelanggan.

e. Arus pendapatan yang menggambarkan uang tunai yang didapatkan perusahaan dari segmen pelanggan.

f. Sumber daya kunci yang menggambarkan aset penting yang diperlukan agar model bisnis agroindustri dapat berfungsi.

g. Aktivitas kunci yang menggambarkan kegiatan terpenting yang dijalankan agroindustri agar model bisnis yang dimiliki dapat bekerja.

h. Kemitraan utama yang menggambarkan jaringan pemasok dan mitra yang membuat model bisnis yang dimiliki agroindustri dapat bekerja.

i. Struktur biaya yang menggambarkan keseluruhan biaya yang dikeluarkan oleh agroindustri dalam mengoperasikan model bisnisnya. 
2. Pengujian masalah

Tahapan yang selanjutnya dilakukan pengujian masalah yang dilakukan untuk mengetahui permasalahan yang dialami oleh responden dan untuk mengetahui hipotesis yang sudah dibuat sudah sesuai atau belum terhadap permasalahan yang dialami. Pengujian masalah ini dilakukan dengan memberikan kuesioner kepada 100 responden yang terdiri atas konsumen dan potensial market dari gula kelapa kristal beriodium.

3. Pengujian solusi

Pengujian solusi kemudian dilakukan setelah dilakukannya pengujian masalah. Pengujian solusi yang dilakukan untuk mengetahui hipotesis yang sudah dibuat dari model bisnis tersebut sudah dapat menyelesakan permasalahan di masyarakat atau belum. Tahapan ini kembali dilakukan pada 100 responden yang sama dengan saat dilakukannya pengujian masalah.

4. Verifikasi model bisnis kanvas

Verifikasi model bisnis kanvas ini merupakan tahapan akhir dari penelitian ini. Verifikasi ini memiliki tujuan kesusian model bisnis yang dibuat dengan pasarnya. Perubahan model bisnis dan pengujian kembali dilkakan jika hasil verifikasi belum sesuai, sedangkan jika sudah sesuai maka berlanjut ke tahap validasi model bisnis.

\section{HASIL DAN PEMBAHASAN}

\section{Hipotesis Model Bisnis Kanvas}

Hasil wawancara dengan pihak manajemen agroindustri gula kelapa beriodium dijadikan sebuah hibotesis model bisnis. Hasil hipotesis tersebut dapat dilihat sebagai berikut:

1. Segmen pelanggan

Segmen pelanggan pada hipotesis awal agroindustri gula kelapa kristal beriodium adalah:

a. Gangguan Akibat Kekurangan Iodium

Pemilihan tersebut didasarkan pada keunggulan produk yaitu adanya fortifikasi iodium pada produk. Iodium merupakan mineral penting dibutuhkan oleh tubuh, sehingga jika terjadi defisiensi iodium pada tubuh maka akan terjadi gangguan kesehatan seperti keguguran, cacat bawaan, kretin, maupun hipotiroid (Karwiti et al., 2018).

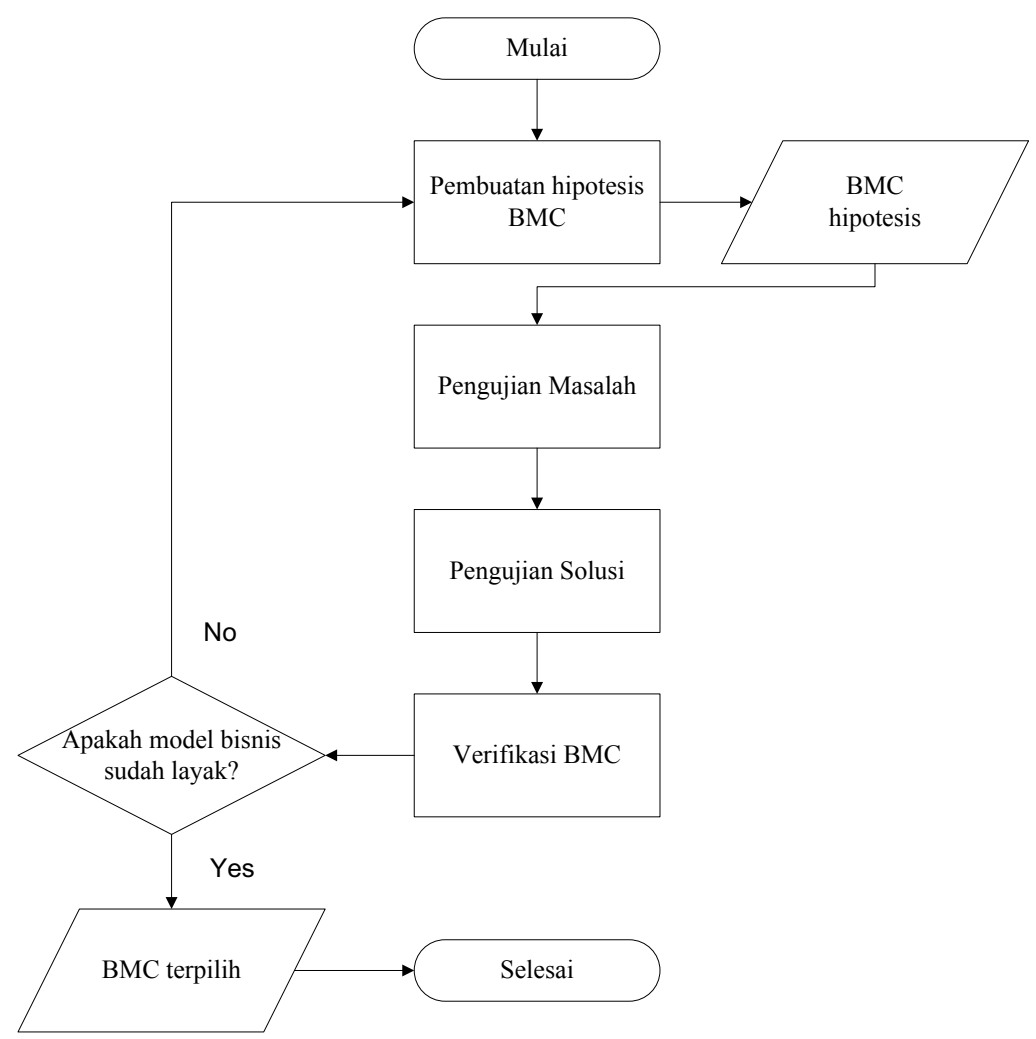

Gambar 1. Diagram alir penelitian 
b. Keturunan diabetes

Menurut Nusa (2017), gula kelapa kristal memiliki kandungan Indeks Glikemiks (IG) rendah, yaitu 52. Produk dengan IG yang rendah baik untuk membantu mencegah terjadinya diabetes.

c. Konsumen gula kelapa

Produk gula kelapa beriodium ini memiliki memiliki keunggulan dengan adanya kandungan iodium dan nilai IG yang rendah jika dibandingkan dengan gula kelapa cetak dan gula kelapa Cair yaitu sebesar 67 dan 54 (Nusa, 2017). Menurut Fadhillah et al. (2020), keunggulan lainnya yaitu mudah larut sehingga praktis dalam penyajiannya, mudah dikemas, mudah dibawa, dan daya simpannya lebih lama karena memiliki bentuk serbuk. Hal tersebut diharapkan dapat menarik minat konsumen gula kelapa cetak, gula kelapa cair, ataupun gula kelapa kristal non fortifikasi iodium untuk beralih ke produk gula kelapa. kristal beriodium.

2. Proporsi nilai

Proporsi inilai yang dimiliki oleh gula kelapa krital beriodium adalah produk yang memiliki manfaat yaitu adanya kandungan iodium dan nilai IG rendah, kepraktisan, serta daya simpan yang lebih lama. Kelebihan tersebut sudah diteliti oleh tim peneliti dari Universitas Jenderal Soedirman. Kelebihan lain yang dimiliki oleh gula kelapa kristal beriodium adalah:

a.Proses produksi yang higienis

Kebersihan di sini sangat penting diperhatikan mengingat lokasi produksi dan pemasaran menjadi satu meliputi kebersihan bahan baku, lokasi produksi, hingga pekerja. Menurut Wijayanti et al. (2019), faktor ini penting untuk ditonjolkan karena konsumen menginginkan produk yang higienis, sehingga pihak agroindustri harus memenuhi hal tersebut agar produknya dapat diterima.

\section{b. Paten}

Paten merupakan salah satu nilai yang dimiliki oleh agroindustri gula kelapa kristal beriodium dan merupakan hal yang berharga karena merupakan perlindungan hukum bagi inventor atas kreativitas serta perwujudan karya intelektualnya (Nasir, 2016). Paten ini dapat melindungi konsumen dari pelanggaran yang dilakukan oleh pihak yang tidak baik dalam memperoleh keuntungan (Sulastri et al., 2018).

c. Kemasan yang menarik

Menurut Mufreni (2016) dan Apriyanti (2018), tampilan kemasan (desain, bentuk, dan bahan) produk merupakan salah satu penting bagi penjualan produk. Hal ini dikarenakan kemasan dapat memberikan daya tarik tersendiri bagi konsumen serta pemberi kesan dalam pengambilan keputusan konsumen sebelum melakukan pembelian produk.
3. Saluran

Saluran distribusi dari agroindutri untuk menjangkau pelanggan adalah melalui penjualan langsung (direct selling) dan penjualan melalui sosial media. Proporsi nilai diharapkan dapat sampai ke konsumen melalui saluran distribusi tersebut.

4. Hubungan pelanggan

Upaya yang dapat dilakukan agroindustri gula kelapa kristal beriodium dalam mendapatkan pelanggannya adalah melalui pameran dan melakukan promosi melalui sosial media. Upaya yang dilakukan untuk mempertahankan konsumen yang sudah ada adalah dengan layanan antar dalam kota dan menyediakan layanan customer service.

5. Arus pendapatan

Arus pendapatan dari agroindustri saat ini adalah dari dari hasil penjualan gula kelapa beriodium dengan berbagai ukuran.

6. Sumber daya kunci

Sumber daya kunci yang menjadi hipotesis model bisnis adalah sumber daya teknologi (mesin dan peralatan untuk proses produksi), bahan baku produksi, sumber daya manusia, dan sumber daya intelektual (paten).

7. Aktivitas kunci

Aktivitas kunci ini merupakan aktivitas utama yang dilakukan agroindustri. Agroindustri gula kelapa beriodium ini memiliki aktivitas utama yaitu pengadaan bahan baku, proses produksi, promosi, distribusi, dan pemasaran.

8. Kemitraan utama

Mitra utama ini sangat dibutuhkan dalam pengoperasian agroindustri. Saat ini mitra utama dari agroindustri gula kelapa beriodium adalah produsen gula kelapa kristal. Hal tersebut dikarenakan agar model bisnis dari agroindustri dapat berjalan dengan baik.

9. Struktur biaya

Struktur biaya merupakan potret biaya yang dikeluarkan oleh agroindustri. Struktur biaya dari agroindustri gula kelapa saat ini terbagi menjadi dua bagian, yaitu: biaya tetap dan biaya variable.

\section{Pengujian Masalah}

Pengujian masalah merupakan tahapan kedua yang dilakukan dalam penelitian. Pengujian masalah ini dilakukan kepada 100 responden. Pengujian masalah dilakukan melalui pengisian kuesioner oleh responden. Hasil pengujian masalah dapat dilihat pada Tabel 1.

Berdasarkan hasil pengujian permasalahan tersebut dapat dilihat terdapat tiga permasalahan yang disampaikan oleh responden. Hal tersebut tentunya menyebabkan krisis kepercayaan terhadap produk yang dapat menyebabkan konsumen enggan dalam membeli ataupun mengkonsumsinya. Berdasarkan permasalahan tersebut dibutuhkan solusi untuk 
mengatasinya. Adapun solusi tersebut dapat dilihat pada Tabel 2 .

Tabel 2 menunjukkan solusi-solusi yang dapat dilakukan oleh manajemen agroindustri gula kelapa kristal beriodium agar mendapatkan kepercayaan. Pengurusan izin edar BPOM. Hal tersebut penting dilakukan karena menurut Yulianti dan Mustarichie (2018), izin edar menggambarkan keamanan dan mutu produk yang beredar di pasaran karena hanya diberikan kepada produk pangan yang memenuhi standar keamanan serta mutu. Pengurusan sertifikat halal juga dapat dijadikan solusi dalam menyelesaikan masalah.

Menurut Ilyas (2017), sertifikat serta labelisasi halal dapat memberikan perlindungan, jaminan, dan informasi kehalalan produk mengingat masyoritas penduduk di Indonesia adalah muslim serta adanya regulasi terkait produk halal telah ada. Perluasan saluran distribusi juga perlu dilakukan agar dapat bersaing dalam merebut pasar sehingga dapat mencapai target usahanya (Putri et al., 2018) mengingat selama ini gula kelapa beriodium hanya dapat dibeli secara langsung di gerainya yang terletak di kompleks kampus Universitas Jenderal Soedirman. Perluasan saluran distribusi tersebut dapat dilakukan dengan konsinyasi agar dapat lebih menghemat biaya, sumber daya manusia, dan supaya pembeli dapat dengan mudah mendapatkan produk di pasaran (Handayani, 2018).

Daftar solusi tersebut dijadikan sebagai bahan dalam melakukan pembaharuan dari hipotesis model bisnis. Perubahan model bisnis terjadi pada dua elemen yaitu proporsi nilai dan saluran distribusi. Hasil pembaharuan tersebut dapat dilihat pada Tabel 3.

\section{Pengujian Solusi}

Pengujian solusi adalah tahap lanjutan yang digunakan untuk mengetahui asumsi yang telah dibuat sudah dapat menyelesaikan permasalahan atau belum. Kegiatan ini dilakukan kepada 100 responden yang sama dengan tahapan sebelumnya. Data didapatkan dari hasil pengisian kuesioner responden mengenai proporsi nilai dan saluran distribusi.

Hasil pengujian solusi terhadap proporsi nilai (izin edar BPOM dan sertifikat halal) menunjukkan bahwa apabila gula kelapa kristal beriodium akan mendapatkan kepercayaan pasar, sebanyak 17 responden (17\%) menyatakan sangat setuju, 71 responden $(71 \%)$ menyatakan setuju, dan sisanya sebanyak 12 responden (12\%) menyatakan netral. Hal ini dikarenakan menurut responden dengan adanya izin edar BPOM dan sertifikat halal, maka responden akan merasa aman dan terlindungi.

Tabel 1. Permasalahan gula kelapa kristal beriodium

\begin{tabular}{|c|c|c|}
\hline No & Jenis Permasalahan & Jumlah Responden \\
\hline 1 & Belum adanya izin edar BPOM & 88 \\
\hline 2 & Belum adanya sertifikat halal produk & 60 \\
\hline 3 & Kemudahan mendapatkan produk & 78 \\
\hline
\end{tabular}

Sumber: data penelitian (2020)

Tabel 2. Daftar solusi yang diberikan untuk menyelesaikan masalah

\begin{tabular}{cll}
\hline No & \multicolumn{1}{c}{ Jenis Permasalahan } & \multicolumn{1}{c}{ Solusi } \\
\hline 1 & Belum adanya izin edar BPOM & Pengurusan izin edar BPOM \\
2 & Belum adanya sertifikat halal produk & Pengurusan sertifikat halal \\
3 & Kemudahan mendapatkan produk & $\begin{array}{l}\text { Memperluas saluran distribusi } \\
\text { (melakukan konsinyasi) }\end{array}$ \\
\hline
\end{tabular}

Sumber: data penelitian (2020)

Tabel 3. Pembaharuan model bisnis gula kelapa kristal beriodium

\begin{tabular}{lll}
\hline \multicolumn{1}{c}{ Komponen } & \multicolumn{1}{c}{ Model Bisnis Awal } & \multicolumn{1}{c}{ Model Bisnis setelah Pembaruan } \\
\hline Proporsi nilai & 1) Manfaat (kandungan iodium & 1) Adanya ijin edar BPOM \\
& dan IG rendah) & 2) Adanya sertifikat halal \\
2) Praktis & 3) Manfaat (kandungan iodium dan IG \\
3) Daya tahan lama & rendah) \\
4) Proses produksi higienis & 4) Paten \\
& 5) Paten & 5) Kemasan menarik \\
6) Kemasan menarik & 1) Penjualan langsung (gerai) \\
1) Penjualan langsung (gerai) & 2) Penjaualan online medsos
\end{tabular}

Sumber: Data penelitian (2020) 
Hasil pengujian terkait solusi terhadap saluran distribusi (konsinyasi) terlihat bahwa gula kelapa kristal beriodium akan mendapatkan kepercayaan pasar, sebanyak 19 responden (19\%) menyatakan sangat setuju, 59 responden (59\%) menyatakan setuju, dan sisanya sebanyak 23 responden (23\%) menyatakan netral. Hasil rekomendasi lokasi yaitu: sebanyak 50 responden (50\%) memilih supermarket/minimarket, 35 responden $(35 \%)$ memilih toko oleh-oleh, dan 15 responden (15\%) memilih apotik/toko obat. Hal ini dikarenakan ketiga lokasi tersebut merupakan lokasi yang mudah dijangkau dan sering dikunjungi oleh responden.

\section{Verifikasi Model Bisnis}

Verifikasi: Kecocokan Produk Dengan Pasar

Komponen ini mengenai produk sudah fokus terhadap pemenuhan kebutuhan atau belum. Hasil pengunkan masalah terhadap 100 responden menunjukkan terdapat permasalahan yang mengakibatkan responden jarang mengkonsumsi gula kelapa kristal beriodium. Hal tersebut diakibatkan konsumen masih ragu terhadap produk karena belum adanya ijin edar BPOM dan belum ada sertifikat halal. Berdasarkan permasalah tersebut maka dilakukan perbaikan sehingga kedepannya dapat menarik minat konsumen sehingga mau mengkonsumsi gula kelapa kristal beriodium.

\section{Verifikasi: Pelanggan Produk Dan Cara Mencapainya}

Cara yang dapat dilakukan manajemen agroindustri untuk dapat menggapai konsumen adalah melalui perluasan saluran pemasaran. Saluran pemasaran tersebut yang menjadi rekomendasi adalah supermarket/minimarket, toko oleh-oleh, dan apotik.

\section{Verifikasi: Apakah Dapat Menghasilkan Uang dan Menumbuhkan Perusahaan?}

Ukuran pasar menjadi faktor dalam analisa peningkatan pendapatan pendapatan agroindustri gula kelapa kristal beriodium. Adapun pasar utama dari produk ini adalah penderita Gangguan Akibat Kekurangan Iodium (GAKI), dimana menurut Kementrian Kesehatan (2019) di Indonesia sebanyak $15-25 \%$ anak usia sekolah (6-12 tahun), wanita usia subur, ibu hamil, dan ibu menyusui berisiko kekurangan iodium. Potensial market lainnya dari produk ini adalah keturunan diabetes dan konsumen gula kelapa.

\section{KESIMPULAN DAN SARAN}

\section{Kesimpulan}

Hasil pengembangan model bisnis yaitu: a) segmen pelanggan meliputi: Gangguan Akibat Kekurangan Iodium (GAKI), keturunan diabet, dan konsumen gula kelapa; b) proporsi nilai meliputi: adanya ijin edar BPOM, adanya sertifikat halal, manfaat (iodium dan IG rendah), paten, dan kemasan menarik; c) saluran distribusi meliputi: penjualan langsung (gerai), konsinyasi (supermarket/ minimarket, toko oleh-oleh dan apotik/toko obat), dan penjualan online (medsos); d) Hubungan pelanggan meliputi: pameran, promosi via medsos, layanan antar dalam kota, dan layanan customer service; e) arus pendapatan meliputi penjualan produk; f) sumber daya kunci meliputi: sumber daya teknologi (mesin dan peralatan produksi), sumber daya manusia, dan sumber daya intelektual (paten); g) aktivitas kunci meliputi: pengadaan bahan baku, proses produksi, ditribusi, dan promosi; h) kemitraan meliputi: produsen gula kelapa kristal; dan i) struktur biaya meliputi: biaya tetap dan variabel.

\section{Saran}

Hasil penelitian ini dapat dijadikan bahan pertimbangan bagi agroindustri gula kelapa kristal beridium dalam melakukan pengembangan model bisnisnya untuk meningkatkan pendapatannya.

\section{UCAPAN TERIMA KASIH}

Ucapan terima kasih penulis sampaikan kepada LPPM Unsoed atas dana penelitian yang diberikan melalui skema Riset Dosen Pemula, sehingga penelitian dapat berjalan dengan baik. Ucapan terima kasih juga disampaikan kepada pihak manajemen Gendis dan tim peneliti yang telah membantu dalam pelaksanaan penelitian.

\section{DAFTAR PUSTAKA}

Apriyanti ME. 2018. Pentingnya Kemasan terhadap Penjualan Produk Perusahaan.

BPS. 2020. Banyumas dalam Angka 2020. Banyumas: Badan Pusat Statistik Kabupaten Banyumas.

Fadhillah N, Mela E, dan Mustaufik. 2020. Gula kelapa kristal dan pemanfaatannya pada produk makanan. AGRITECH. 12(1): 20-28.

Handayani S. 2018. Analisis potensi hasil penjualan terhadap kelancaran pembayaran barang konsinyasi pada toko pakaian pd. pasar tingkat lamongan. Jurnal Penelitian Ekonomi \& Akuntansi. III(3): 863-872.

Herawati N, Lindriati T, dan Suryaningrat ID. 2019. Penerapan bisnis model kanvas dalam penentuan rencana manajemen usaha kedelai edamame goreng. Jurnal Agroteknologi. 13(01): 42-51.

Ilyas M. 2017. Sertifikasi dan labelisasi produk halal perspektif maslahat. Jurnal Al-Qadau Peradilan dan Hukum Keluarga Islam. 4(2): 357-376.

Karwiti W, Basa IH. Asrori, dan Silvia V. 2018. Gambaran kadar iodium (sebagai $\mathrm{KIO}_{3}$ ) dalam garam dapur yang dijual di pasar kota palembang tahun 2017. JPP. 13(2): 98-110. 
Kementrian Kesehatan. 2019. Kekurangan Iodium Masih Saja Menjadi Masalah Kesehatan. Jakarta: Humas Penelitian dan Pengembangan Kesehatan, Badan Penelitian dan Pengembangan Kesehatan.

Mufreni ANF. 2016. Pengaruh desain produk, bentuk kemasan, dan bahan kemasan terhadap minat beli konsumen (Studi Kasus Teh Hijau Serbuk Tocha). JEM. 2(2): 48-54.

Nasir R. 2016. Paten dalam proses produksi: tinjauan hak yang melekat pada inventor. Jurnal Hukum Positum. 1(1): 141-149.

Nurhakim AS, Suparno O, dan Nurrochmat DR. 2018. Pengembangan model bisnis dan strategi pelayanan kesehatan XYZ. Jurnal Aplikasi Manajemen dan Bisnis. 4(2): 251260.

Nusa CP. 2017. Indeks Glikemik Gula Kelapa Cetak, Kristal, dan Cair. [Skripsi]. Bogor: Institut Pertanian Bogor.

Putri MA, Rosmayani, dan Rosmita. 2018. Analisis faktor-faktor yang mempengaruhi saluran distribusi usaha kecil menengah (UKM) (Survei pada Kue Bangkit "Syempana" di Kota Pekanbaru). Jurnal Valuta. 4(2): 117137.

Satriani R dan Sularso KE. 2018. Analisis Nilai Tambah Gula Kelapa Kristal di Kabupaten Banyumas. Prosiding Seminar NasionalPengembangan Sumber Daya Perdesaan dan Kearifan Lokal Berkelanjutan VIII.
Purwokerto, Indonesia, 14-15 November 2018.

Sholihah NA dan Iqbal M. 2018. Analisis perancangan model bisnis dengan pendekatan business model canvas (Studi pada Usaha Kecil Menengah UD. Duta Merpati). JAB. 61(4): 183-191.

Sulastri, Satino, dan Wahyuningsih YY. 2018. Perlindungan hukum terhadap merek (tinjauan terhadap merek dagang Tupperware Versus Tulipware). Jurnal Yuridis. 5(1): 160-172.

Tokarski A, Tokarski M, dan Wojcik J. 2017. The Possibility of using the business model canvas in the establishmen of an operator's business plan. Torun Business Review. 16(4): 17-31.

Wijayanti N, Hidayat HH, Satriani R. 2019. Peningkatan Kualitas Produksi melalui Renovasi Dapur Produksi dan Pelatihan Pengemasan pada IKM Keripik Tempe. Prosiding Seminar Nasional-Pengembangan Sumber Daya Perdesaan dan Kearifan Lokal Berkelanjutan IX. Purwokerto, Indonesia, 1415 November 2019.

Yulianti MD dan Mustarichie R. 2018. Tata Cara Registrasi untuk pangan olahan industri rumah tangga (PIRT) dan makanan dalam negeri (MD) dalam rangka peningkatan produk yang aman dan bermutu di Bandung Jawa Barat. Jurnal Farmaka. 15(3): 57-64 